\title{
Interaction between Aqueous Solutions of Hydrophobically Associating Polyacrylamide and Dodecyl Dimethyl Betaine
}

\author{
Zhongbin Ye, ${ }^{1,2}$ Guangfan Guo, ${ }^{3}$ Hong Chen, ${ }^{1}$ and Zheng Shu ${ }^{3}$ \\ ${ }^{1}$ State Key Laboratory of Oil and Gas Reservoir Geology and Exploitation, Southwest Petroleum University, \\ Chengdu, Sichuan 610500, China \\ ${ }^{2}$ School of Chemistry and Chemical Engineering, Southwest Petroleum University, Chengdu, Sichuan 610500, China \\ ${ }^{3}$ School of Petroleum Engineering, Southwest Petroleum University, Chengdu, Sichuan 610500, China
}

Correspondence should be addressed to Guangfan Guo; 383821889@qq.com

Received 5 November 2013; Revised 1 January 2014; Accepted 8 January 2014; Published 23 February 2014

Academic Editor: Shin-ichi Yusa

Copyright (C) 2014 Zhongbin Ye et al. This is an open access article distributed under the Creative Commons Attribution License, which permits unrestricted use, distribution, and reproduction in any medium, provided the original work is properly cited.

\begin{abstract}
The interaction between hydrophobically associating polyacrylamide (HAPAM) and dodecyl dimethyl betaine (BS-12) is studied through surface tension, interfacial tension (IFT), apparent viscosity, aggregation behavior, and microscopic morphologies. Results show that surface and interface properties of BS-12 are largely affected by HAPAM. BS-12 critical micelle concentrations are increased with the increment of polymer concentrations. Abilities of reduced air-water surface tension and oil-water interfacial tension are dropped. The oil-water interfacial tension to reach minimum time is increased. HAPAM can form network structures in the aqueous solution. Mixed micelles are formed by the interaction between BS-12 micelles and hydrophobic groups of HAPAM in aqueous solution and self-assembly behavior of HAPAM is affected. With the increment of surfactant concentrations, the apparent viscosity, apparent weight average molecular weights $\left(M_{w, a}\right)$, root mean square radius of gyration $\left(\left\langle R_{g}\right\rangle\right)$, and hydrodynamic radius of HAPAM increase first and then decline. Moreover, microscopic morphologies of the mixed system are formed from relatively loose network structures to dense network structures and then become looser network structures and the part of network structures fracture.
\end{abstract}

\section{Introduction}

Water-soluble polymers modified with a small amount of hydrophobic groups $(<2 \%$, mole fraction) have become of great interest in recent years. They have broad application prospects, such as oil exploration, paint, mineral separation, and cosmetic and pharmaceutical preparations et al. [1-4]. Hydrophobically associating polymer molecules in aqueous solution, three-dimensional network structures are formed through the intermolecular interaction. Therefore, hydrophobically modified polymers have the good increasing viscosity, heat resistance, salt resistance and shear resistance, and so on [5-7], and they have a good application prospect.

Polymer-surfactant mixed system is a kind of very important soft substance. Usually adding surfactants into polymer solutions, the dosage of polymers or surfactants can be reduced, and solution performances are improved [8-10]. The mixed system has many unique properties, for example, the system viscosity, interfacial adsorption, solubilization, drug delivery, and so on. So the study of polymer-surfactant mixed system is that people are very interested in research subjects [11-14]. In recent years, the interaction between hydrophobically associating polyacrylamide (HAPAM) and surfactant is studied by some scholars [15-18]. These studies find that the system can form mixed micelles and rheological properties of polymer solutions can be changed to a great extent. The interaction between polymer and surfactant is mainly decided by the polymer hydrophobicity and the surfactant structure. Betaine is a main type of zwitterionic surfactant. It shows characteristics of different ionic surfactant under different conditions owing to having anionic and cationic groups at the same time. Now the interaction between HAPAM and betaine surfactants is very little researched [19]. In this paper, the interaction of hydrophobically associating polyacrylamide (HAPAM) and dodecyl dimethyl betaine is studied. Expecting polymer-surfactant mixed system has 


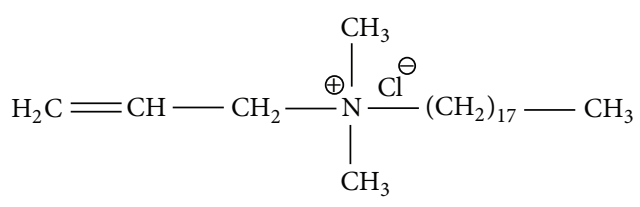

FIGURE 1: Molecular structure of 18-alkyl-dimethyl diallyl ammonium chloride $\left(\mathrm{C}_{18}\right.$ DMAAC).

good application prospects in washing textile, daily chemical and oil field development, and so on.

\section{Experiment}

2.1. Materials and Instruments. Acrylamide (AM), acrylic acid (AA), anhydrous sodium carbonate $\left(\mathrm{Na}_{2} \mathrm{CO}_{3}\right)$, potassium persulfate $\left(\mathrm{K}_{2} \mathrm{~S}_{2} \mathrm{O}_{8}\right)$, and sodium hydrogen sulfite $\left(\mathrm{NaHSO}_{3}\right)$ were provided by Chengdu Kelong Chemical Reagents Corporation, China, and all drugs were analytical pure. 18-Alkyl-dimethyl diallyl ammonium chloride $\left(\mathrm{C}_{18}\right.$ DMAAC, its molecular structure be shown in Figure 1) and dodecyl dimethyl betaine (BS-12) were supplied by Southwest Petroleum University. TX-500C full range tensiometer was purchased from the United States Bowing Industry Corporation. Brookfield DV-III viscometer was purchased from the United States Brookfield Instrument Corporation. BI-200SM dynamic/static wide angle laser light scattering apparatus was purchased from the United States Brooke Haven Instrument Corporation. Nanoscope IIIa atomic force microscope was purchased from the United States Digital Instrument Corporation.

\subsection{Synthesis of Hydrophobically Associating Polyacrylamide.} Hydrophobically associating polyacrylamide (HAPAM) synthesis is as follows. $80 \mathrm{~g}$ distilled water, $14.9 \mathrm{~g}$ acrylamide (AM), $5 \mathrm{~g}$ sodium acrylate (acrylic acid and anhydrous sodium carbonate), and $0.1 \mathrm{~g} 18$-alkyl-dimethyl diallyl ammonium chloride $\left(\mathrm{C}_{18}\right.$ DMAAC) were added into a three-necked flask according to the literature [20]. Adjusting the $\mathrm{pH}$ value of the system was 6.0-7.0, and potassium persulfate/sodium hydrogen sulfite redox $(0.03 \%-0.05 \%)$ were added. The solution was mixed and then bubbled with nitrogen for $30 \mathrm{~min}$ to displace dissolved oxygen then quickly capped. The polymerization was carried out at $50^{\circ} \mathrm{C}$ for $24 \mathrm{~h}$. Products were precipitated and purified by ethanol to remove unreacted monomers and oligomers and then were baked in a vacuum drying oven at the $50^{\circ} \mathrm{C}$ to constant quality. The polymer molecular structure was shown in Figure 2, and characteristic parameters were shown in Table 1.

2.3. Solution Preparation. The aqueous solutions (5000 ppm) of surfactant and polymer were always freshly prepared using a mechanical stirrer for $8-10 \mathrm{~h}$ to form a consistent homogeneous solution at a low rotation per minute. Appropriate quantity of zwitterionic surfactants and hydrophobically associating polymers were dissolved carefully in distilled water for about $40 \mathrm{~min}[21,22]$.

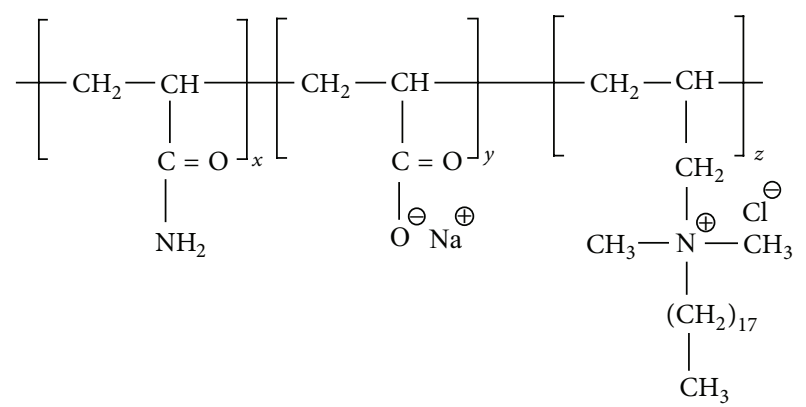

FIGURE 2: Molecular structure of hydrophobically associating polyacrylamide (HAPAM) (theoretical mole percents of $x, y$, and $z$ were about $79.7 \%, 20.2 \%$, and $0.1 \%$, resp.).

\subsection{Measurement of Surface Tension and Interfacial Tension.} In polymer-surfactant mixed systems, polymer concentrations were 500,1000, 1500, and $2000 \mathrm{ppm}$, respectively, and BS-12 concentrations were 10-2000 ppm. The surfactant solution with or without HAPAM as outer-phase was injected into the glass tube, and $2 \mu \mathrm{L}$ air or oil as inner-phase was put into the middle of the tube. Then the tube was enveloped with the plastic cover and put into the apparatus measuring the surface tension or interfacial tension at a temperature of $25^{\circ} \mathrm{C}$ [3]. In surface tension experiment, the outer-phase was polymer-surfactant mixed system and the inner-phase was air. Surface tensions of polymer-surfactant mixed systems were measured at a rotating velocity of $6000 \mathrm{rpm}$, when surface tension reached a minimum value and stopped the test. In interfacial tension (IFT) experiment, the outer-phase was polymer-surfactant mixed system and the inner-phase was dodecane. Interfacial tensions of mixed systems were measured at a rotating velocity of $5000 \mathrm{rpm}$, when interfacial tension reached a minimum value and stopped the test. In dynamic interfacial tension (DIFT) experiment, surfactant concentration was selected to make oil-water interfacial tension minimum in different polymer concentrations, and then interfacial tensions of the mixed system as time changing were measured a at a rotating velocity of $5000 \mathrm{rpm}$.

2.5. Measurement of Apparent Viscosity. In polymer-surfactant mixed systems, the polymer concentration was $1500 \mathrm{ppm}$ and BS-12 concentrations were $10-2000 \mathrm{ppm}$. The viscosities of polymer-surfactant mixed systems were measured by Brookfield DV-III viscometer with a shearing rate of $7.34 \mathrm{~s}^{-1}$ and at a temperature of $25^{\circ} \mathrm{C}$.

2.6. Laser Light Scattering Experiment. The diluted polymersurfactant mixed system was dusted and filtered by the Millipore Corporation production of the disposable filter with a $0.8 \mu \mathrm{m}$ aperture. The filtrate was collected in the sample pool. In the laser light scattering experiment, toluene as a standard solution, the laser wavelength was $532 \mathrm{~nm}$ and the measured temperature was $25^{\circ} \mathrm{C}[23,24]$.

According to the light scattering theory [25-27], weight average molecular weight $\left(M_{w}\right)$ and root mean square radius of gyration $\left(\left\langle R_{g}\right\rangle\right)$ of polymers were measured by static light 
TABLE 1: Characteristic parameters of hydrophobically associating polyacrylamide (HAPAM).

\begin{tabular}{lcccc}
\hline Sample & Molecular weight & $\begin{array}{c}\text { Degree of } \\
\text { hydrolysis }(\%)\end{array}$ & $\begin{array}{c}\text { Critical association } \\
\text { concentration }(\mathrm{ppm})\end{array}$ & Polydispersity index \\
\hline HAPAM & 6000000 & 25.0 & 800 & 1.46 \\
\hline
\end{tabular}

scattering. For high molecular weight polymers, the light scattering of polymer dilute solution can be expressed as:

$$
\begin{aligned}
\left(\frac{K C}{R_{v v}(q)}\right)^{1 / 2} \approx & \left(\frac{1}{M_{W}}\right)^{1 / 2}\left(1+\frac{1}{6}\left\langle R_{g}^{2}\right\rangle q^{2}\right) \\
& \times\left(1+A_{2} M_{w} C\right),
\end{aligned}
$$

where $K=4 \pi^{2} n_{0}^{2}(d n / d C)^{2} /\left(N \lambda_{0}^{4}\right), K$ was associated with the constant of solvent nature and incident light frequency; $n_{0}$ was the refractive index of solution; $C$ was the solution concentration, $\mathrm{ppm} ; R_{v v}(q)$ was the solvent effect of scattering intensity for different angles; $\lambda_{0}$ was the incident light wavelength; $\lambda$ was the wavelength of incident light in solution, $\lambda=\lambda_{0} / n_{0} ; d n / d C$ was the refractive index increment and the ratio of solution refractive index and concentration, ppm; $N$ was the Avogadro constant; $\left\langle R_{g}\right\rangle$ was root mean square radius of gyration and the chain quality centre to each chain segment average of squared distance. When the scattering angles were $\theta \rightarrow 0$ and concentrations were $C \rightarrow 0$, some parameters were obtained such as $\left\langle R_{g}\right\rangle$ and $M_{w}$ by extrapolation [28, 29].

Hydrodynamic radius $\left\langle R_{h}\right\rangle$ of polymer molecules under different surfactant concentrations was measured by dynamic light scattering (DLS) [24]. In the dynamic light scattering, measurements were the light intensity-light intensity time related spectroscopy:

$$
G^{(2)}(\tau)=A \cdot\left(1+\beta \cdot\left|g^{(1)}(\tau)\right|^{2}\right),
$$

where $G^{(2)}(\tau)$ was the autocorrelation function of light intensity; $A$ was the baseline of the autocorrelation function; $\beta$ was the experimental constant of constraint signal noise ratio, associated with the measuring experimental device; $g^{(1)}(\tau)$ was autocorrelation function of electric field. Its relationship with the line width distribution $G(\Gamma)$ is as follows:

$$
g^{(1)}(\tau)=\int_{0}^{\infty} G(\Gamma) \exp (-\Gamma \tau) d \Gamma .
$$

If the relaxation is caused entirely by diffusion, under the conditions of $C \rightarrow 0$ and $q \rightarrow 0, \Gamma=D q^{2}, D$ was the particle diffusion coefficient and $q$ was the scattering vector. This moment, when the concentration was very low, $D$ extrapolated to zero point and particle size distributions were obtained through Stokes-Einstein formulas $D=$ $K_{B} T /(3 \pi \eta d)$, where: $K_{B}$ was Boltzmann constant; $T$ was absolute temperature; $\eta$ was solvent viscosity; $d$ was particle diameter.

2.7. Measurement of Molecular Aggregation Morphologies. AFM operating mode was tapping; Probe model was RTESP; operating frequency was $86 \mathrm{kHz}$; force constants were
$1 \sim 5 \mathrm{Nm}^{-1}$. The system was stirred at a low velocity for $5 \mathrm{~min}$ to obtain a homogeneous solution concentration. For the AFM measurements, $0.1 \mathrm{~mL}$ of the prepared polymer-surfactant mixed system was dropped onto freshly cleaved mica, and the redundant solution was blown off by a stream of high purity nitrogen. Samples were measured by Nanoscope IIIa microscope in air at the ambient temperature [30].

\section{Results and Discussions}

3.1. Surface Tension of Polymer-Surfactant Mixed System. It is well known that surfactants reduce the surface tension of water by getting adsorbed on the liquid-gas interface. The $\mathrm{CMC}$, one of the main parameters for surfactants, is the concentration at which surfactant solutions begin to form micelles in large amounts [22]. Different techniques are used to examine the water-soluble polymer-surfactant aggregates formed in solution [31,32]. Surface tensions of surfactant (BS12) solutions at different concentrations were measured and plotted as a function of concentrations (Figure 3). Figure 3 shows that the CMC and the surface tension have been a large change after adding polymers into surfactant solutions. When polymers are not added, the CMC and the CMC of the surface tension are minimal. The CMC value of BS-12 is about $300 \mathrm{ppm}$ and the surface tension is about $31.3 \mathrm{mN} / \mathrm{m}$. After the polymers being added, the surfactant $\mathrm{CMC}$ and the CMC of surface tensions gradually increase with the increment of polymer concentrations. When HAPAM concentration is about $2000 \mathrm{ppm}$, the CMC of the mixed system is about $500 \mathrm{ppm}$ and the surface tension increases to $33.4 \mathrm{mN} / \mathrm{m}$. Khan et al. also found the same behavior of polyacrylamide solutions in the presence of SDBS [22]. The reason for this phenomenon is that hydrophobic groups of polymers will interact with surfactant hydrophobic parts, and some surfactants are shackled in the bulk phase. Shackled surfactants increase with the increment of polymer concentrations. They need to consume more surfactants to form micelles [3]. Therefore, reaching critical micelles requires higher surfactant concentrations. Mixed micelles of polymers/surfactants that are formed have been inhibitory effect to the surface tension of surfactants in solution.

3.2. Interfacial Tension of Polymer-Surfactant Mixed System. The polymer-surfactant mixed system has been applied in the oil field owing to reducing the mobility ratio decrease interfacial tension (IFT) between the water and the oil [33, 34]. It has been reported that addition of polymers increases the IFT of ionic surfactants $[3,35]$. Interfacial tensions of surfactant (BS-12) solutions at different concentrations are measured, and results are shown in Figure 4. Figure 4 shows that oil-water IFT is decreased with the increment of surfactant concentrations. After a turning point, the IFT 


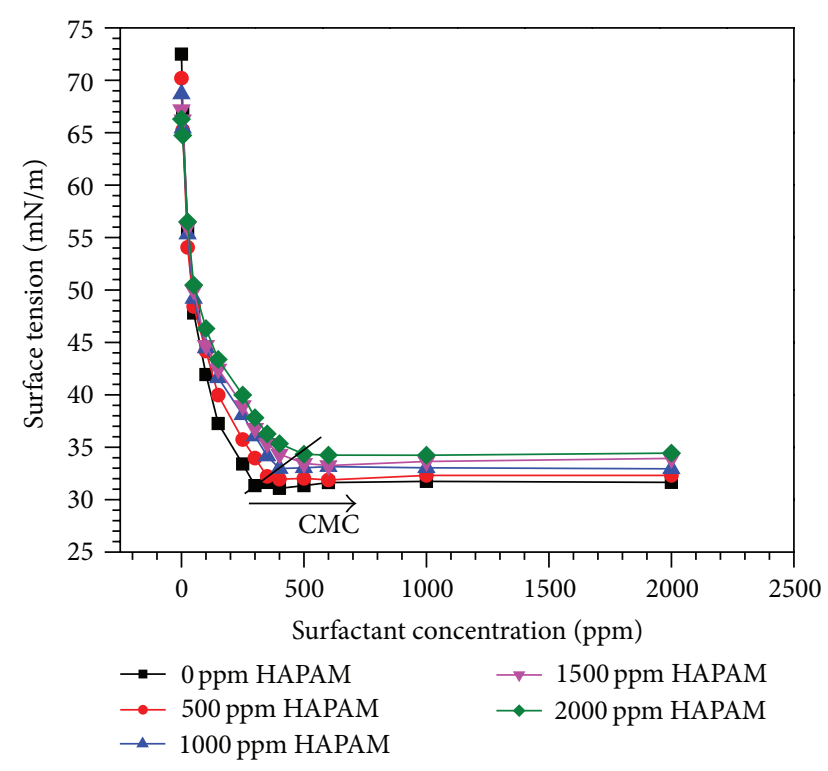

FIGURE 3: Effect of HAPAM concentrations on surface tensions of BS-12.

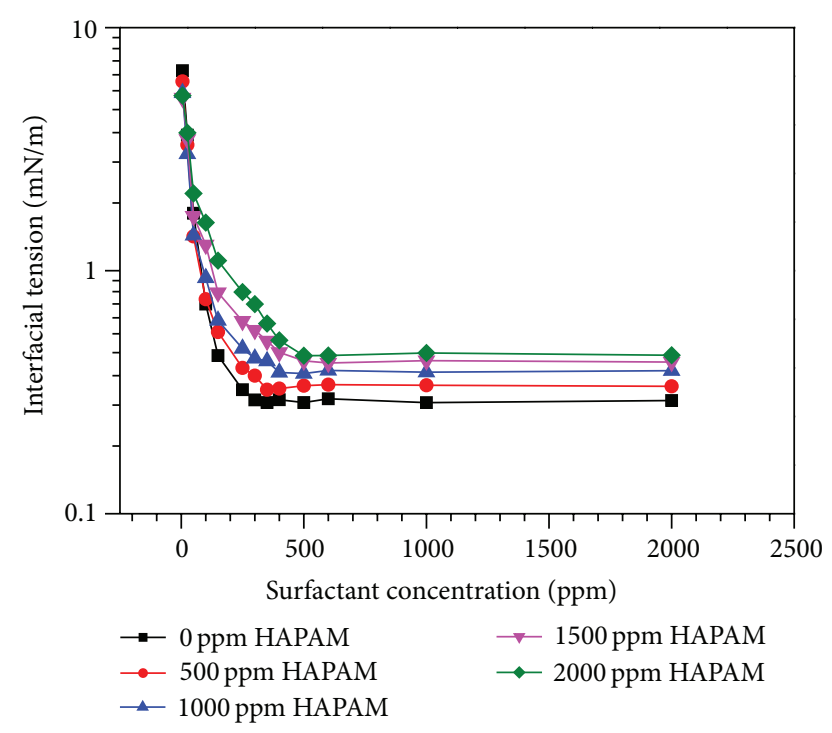

FIGURE 4: Effect of HAPAM concentrations on interfacial tensions of BS-12.

becomes to balance. If there are no polymers, the turning point of surfactant concentration and the IFT is minimal. The turning point of surfactant concentration is about $300 \mathrm{ppm}$ and the IFT is about $0.29 \mathrm{mN} / \mathrm{m}$. With the increment of polymer concentrations, the turning point of surfactant concentration and the IFT have shown a trend of increment. This phenomenon is similar to Figure 2. Hydrophobic groups of polymers will interact with surfactant hydrophobic parts and bound part surfactants in the bulk phase. Ultimately, the ability of reduced oil-water IFT is declined. The shackled effect is enhanced with the polymer concentrations increasing. Therefore the reduced oil-water IFT needs to consume more surfactants. On the other hand, the IFT of surfactants

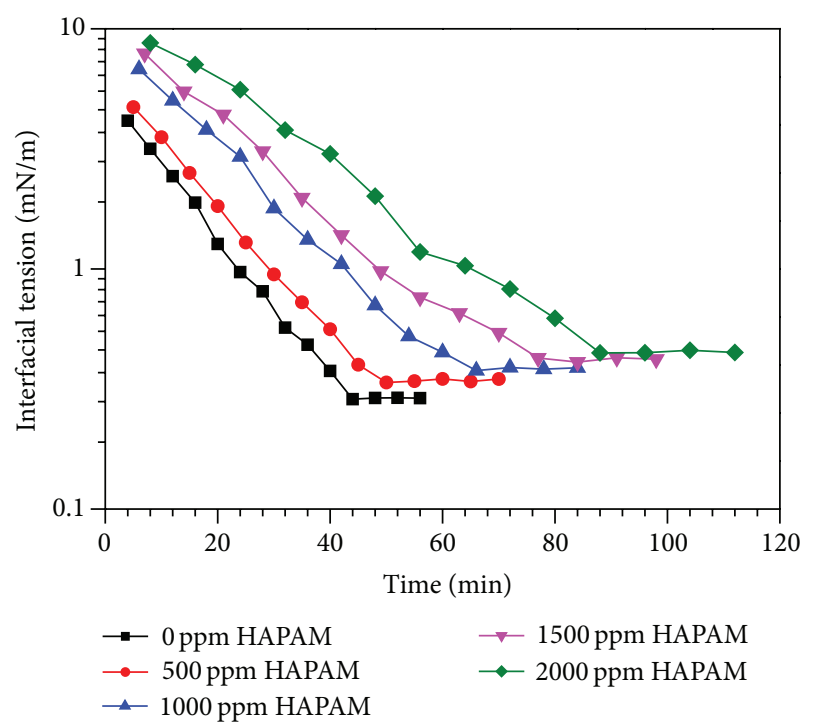

FIGURE 5: Effect of HAPAM concentrations on the dynamic interfacial tensions of BS-12.

can be inhibited by the viscosity of polymer solutions. Chen et al. also confirm the result [3].

Figure 5 shows the result that the oil-water dynamic interfacial tension (DIFT) of BS-12 is affected by the HAPAM concentrations. The DIFT is changed with time increasing. The reduced surfactant IFT and reaching steady state that required time can be reflected by DIFT characteristics. When surfactant concentrations are $500 \mathrm{ppm}$, the DIFT change is faster at lower polymer concentrations. Therefore oil-water IFT reaching a minimum need less time. The higher concentrations the polymer is, the longer the time reaching a minimum of IFT is. The reason is that surfactants and associating polymers have the strong interaction and oil-water interface diffusion rates of surfactants which are significantly affected. In addition, the system viscosity increases with the increment of polymer concentrations, and the surfactant spread speed is also slowed. As a result, the IFT reaching a minimum needs longer times at the higher polymer concentrations.

3.3. Apparent Viscosity of Polymer-Surfactant Mixed System. The effect of BS-12 concentrations on the viscosity of polymers is shown in Figure 6. Figure 6 shows that the system viscosity increases first and then declines with the increment of BS-12 concentrations. When the BS-12 concentration is about 100 ppm, the system viscosity is the largest. Badoga et al. [36] and Jiang et al. [37] have reported that the viscosity of polymer-surfactant mixed systems increases first and then declines with the increment of surfactant concentrations. When the addition of surfactant concentrations is lower, surfactant molecules in single molecule state are distributed in aqueous solution. Surfactant molecular ions and HAPAM molecular chains interacting with each other make the interaction of hydrophobic groups forming inner salt keys be opened, and the intermolecular association is formed. At this moment, the association between polymer molecules promoted role and polymer molecular chains is more diastolic 


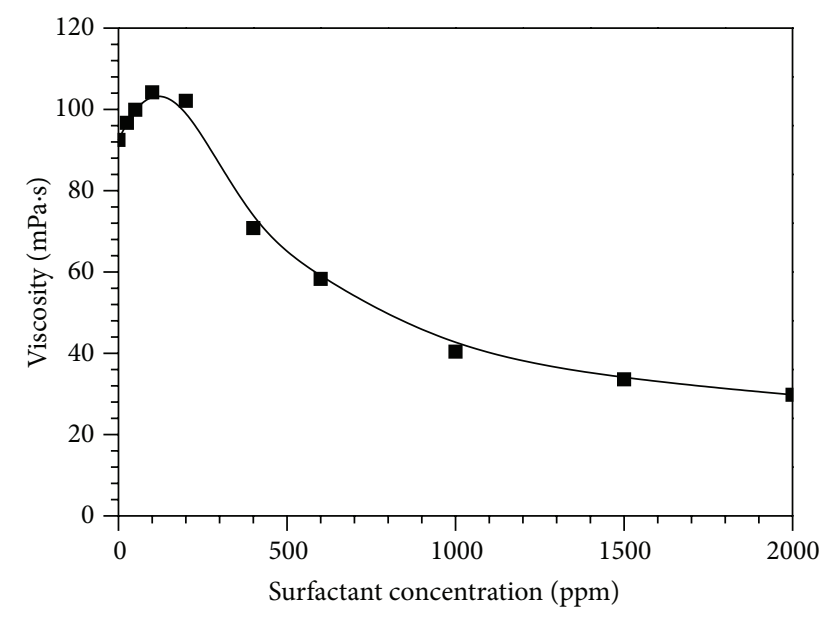

FIGURE 6: Effect of BS-12 concentrations on the viscosity of 1500 ppm HAPAM.



FIGURE 7: Effect of BS-12 concentrations on apparent weight average molecular weight $\left(M_{w, a}\right)$ of HAPAM.

because of the addition of surfactants. The solution viscosity is increased with the increment of surfactant concentrations. When surfactant concentrations exceed a certain value, the interaction between surfactants and hydrophobic groups of polymer chain segments is further enhanced. Mixed micelles of polymer-surfactant are formed. On the other hand, the intermolecular association of polymers is shielded with the increase of surfactant micellar numbers; thus polymer network structures are damaged and collapsed. The viscosity of mixed systems is decreased.

3.4. Laser Light Scattering Experiments. It has been reported $[23,38]$ that addition of ionic surfactants influences the molecular structure of the polymer. The effects of BS-12 concentrations on apparent weight average molecular weights $\left(M_{w, a}\right)$ of polymers are tested at a $25^{\circ} \mathrm{C}$. Their result is shown in Figure 7. The root mean square radius of gyration $\left(\left\langle R_{g}\right\rangle\right)$ is characteristic parameters of the polymer and directly reflects the conformation of polymer chains. In order to

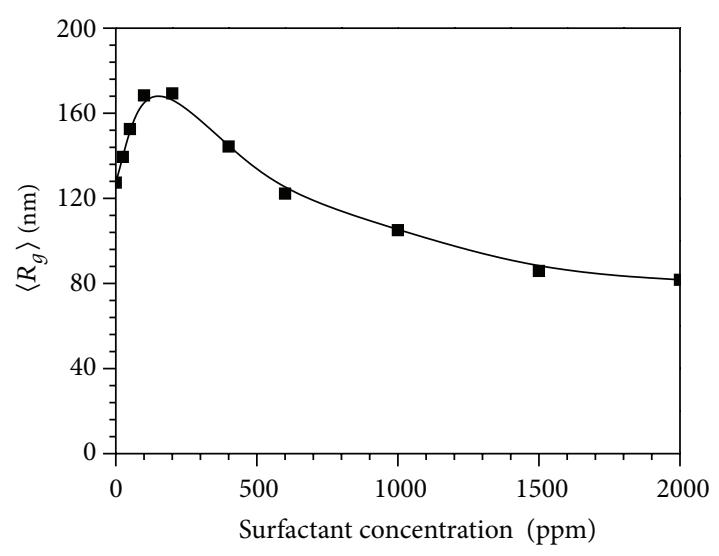

FIGURE 8: Effect of BS-12 concentrations on root mean square radius of gyration $\left(\left\langle R_{g}\right\rangle\right)$ of HAPAM.

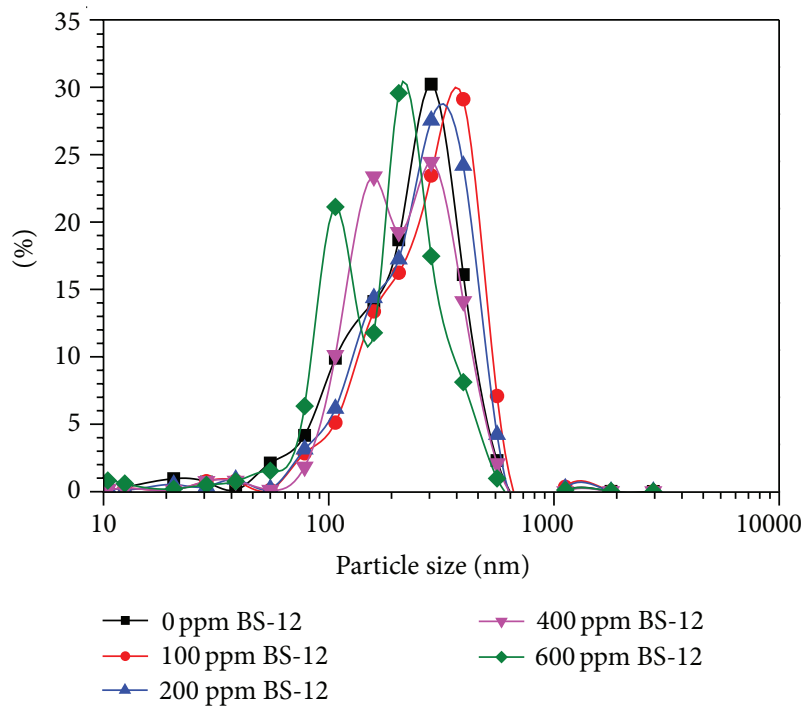

FIGURE 9: Particle size distributions of HAPAM with different BS-12 concentrations.

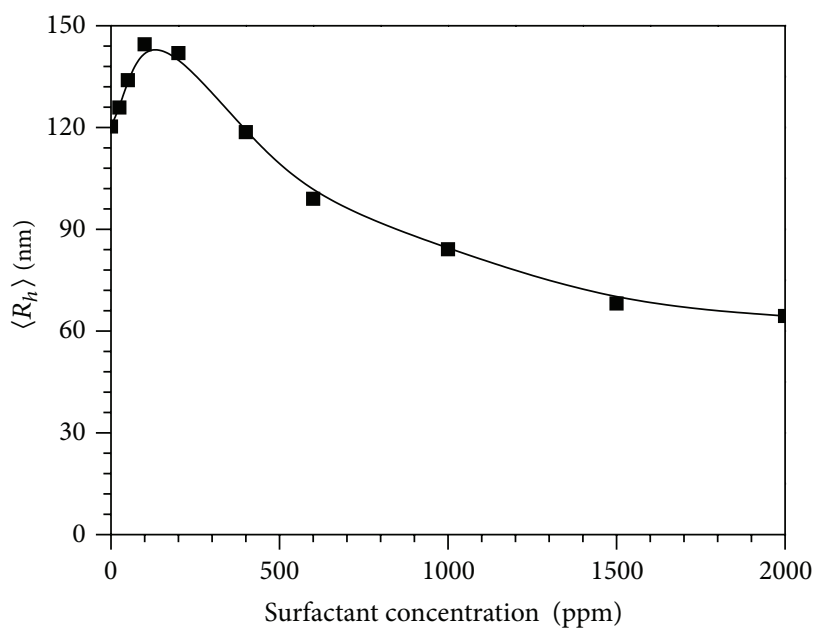

FIGURE 10: Effect of BS-12 concentrations on the hydrodynamic radius $\left(\left\langle R_{h}\right\rangle\right)$ of HAPAM. 


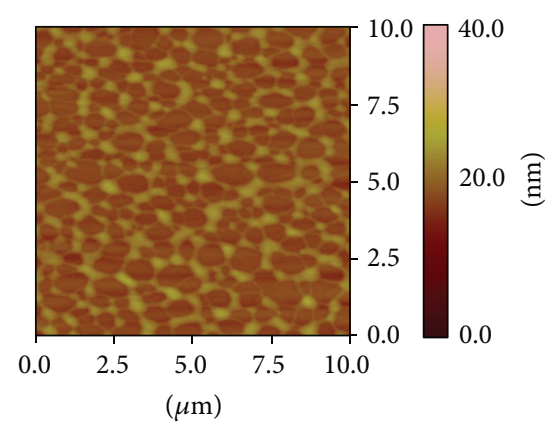

(a)

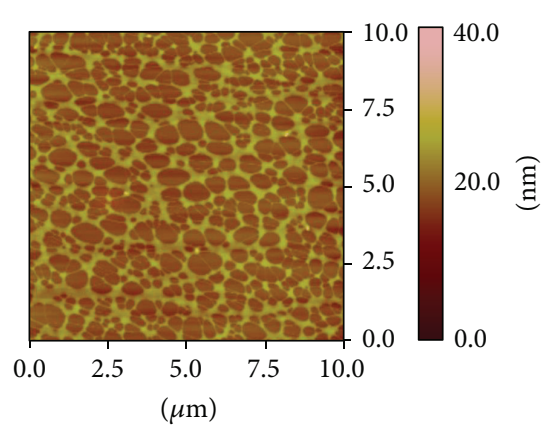

(b)

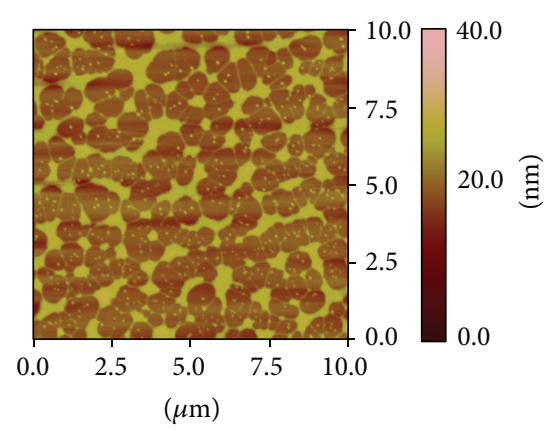

(c)

FIGURE 11: AFM images of 1500 ppm HAPAM with different BS-12 concentrations: (a) 0 ppm BS-12, (b) 100 ppm BS-12, and (c) 400 ppm BS-12.

reduce the effect of polymer concentrations, the preparation concentration of polymers is $2 \mathrm{ppm}$ in experiment. For the dilute polymer solution, $\left\langle R_{g}\right\rangle$ can be concluded through extrapolation of the same concentrations with different angles in solution; then some $\left\langle R_{g}\right\rangle$ are received under different surfactant concentrations in the same way. Their results are shown in Figure 8.

Figures 7 and 8 show that $M_{w, a}$ and $\left\langle R_{g}\right\rangle$ of HAPAM increase first and then decline with the increment of BS12 concentrations. When there are a few surfactants in the polymer-surfactant mixed system, the surfactant molecules interacting with polymer hydrophobic groups, intermolecular association of polymers is strengthened and polymers are more likely to gather to form super molecular structures. $M_{w, a}$ and $\left\langle R_{g}\right\rangle$ show a trend of increment. When surfactant concentrations are about $100 \mathrm{ppm}$, the system viscosity is the largest. With the further increment of surfactant concentrations, hydrophobic groups of polymer molecules are inhibited by cationic groups of surfactant molecular chains. The intramolecular association of associating polymers forms inner salt key. $M_{w, a}$ and $\left\langle R_{g}\right\rangle$ become smaller. When surfactant concentrations are more than its critical micelle concentrations, the number of surfactant micelles is increased. Hydrophobic groups of associating polymers are separated by surfactant micelles. The intermolecular association is weakened and supramolecular aggregations are dismantled. Thus, $M_{w, a}$ and $\left\langle R_{g}\right\rangle$ are further smaller.

In order to study zwitterionic surfactant (BS-12) effect on hydrodynamic sizes of polymers in solution, the preparation concentration of polymers is $2 \mathrm{ppm}$ in the experiment. Particle size distributions and hydrodynamic radius $\left(\left\langle R_{h}\right\rangle\right)$ of the polymer under different surfactant concentrations are measured by dynamic light scattering at a $25^{\circ} \mathrm{C}$ and the scattering angle is $90^{\circ}$. Their results are shown in Figures 9 and 10. Figure 9 shows that particle sizes of HAPAM are unimodal distribution under no surfactant condition. When surfactant concentrations are about $100 \mathrm{ppm}$, the particle size distribution of HAPAM is a wider unimodal and moves to the right. Surfactants can enhance intermolecular association of polymers and make polymer chains stretch and hydrodynamic radius increase. When surfactant concentrations are more than $400 \mathrm{ppm}$, particle sizes of HAPAM are multimodal distributions and wider unimodal move to left. The reason is that surfactant micelles are increased with the increment of surfactant concentrations in solution. Some polymer hydrophobic groups are embedded by surfactant micelles. The intermolecular association of HAPAM is partially blocked, and the hydrodynamic radius appears to be reducing.

Figure 10 shows that $\left\langle R_{h}\right\rangle$ is increased because of a small amount of surfactants to be added. When surfactant concentrations are lower, the intermolecular association of HAPAM is strengthened, and $\left\langle R_{h}\right\rangle$ is increased. But the surfactant concentrations exceed a certain value; polymer aggregations are dismantled; therefore, $\left\langle R_{h}\right\rangle$ is reduced.

3.5. Molecular Aggregation Morphologies of Polymer-Surfactant Mixed System. The previous research results had been confirmed that space network structures of hydrophobically associating polymer are formed exceeding the critical association concentration (CAC) of polymer [3, 24]. When ionic surfactants are added, molecular aggregation morphologies of HAPAM are affected. Different BS-12 concentrations affecting molecular aggregation morphologies are observed. Their results are shown in Figure 11. Figure 11(a) is an AFM photo of HAPAM without surfactants. When the HAPAM concentration exceeds the CAC, it can be formed obvious spatial network structures in distilled water [39]. Figure 11(b) is an AFM photo of HAPAM solution to add 100 ppm surfactants. Compared with Figures 11(a) and 11(b), when BS-12 concentrations are about $100 \mathrm{ppm}$, the space network structures become more intense in solution, and the connecting mesh chain beams are thicker, especially the intersection part of chain beam. Figure 11(c) is an AFM photo of HAPAM solution to add 400 ppm surfactants. Compared with Figures 11(b) and 11(c), when BS-12 concentrations are about $400 \mathrm{ppm}$, the space network structures become sparser. When surfactants continue to be added, the connecting network chain beams are thinner. These results show that adding a few surfactants has a promoting effect on the self-assembly of polymer molecules, but the self-assembly of polymer molecules is inhibited for adding too many surfactants.

\section{Conclusions}

(1) Adding polymers into dodecyl dimethyl betaine (BS12) solutions, the CMC and surface tensions of the 
CMC are increased with the increment of HAPAM concentrations.

(2) Zwitterionic surfactant (BS-12) can reduce dodecanoic-water interfacial tension to about $0.3 \mathrm{mN} / \mathrm{m}$. BS12 has been a good ability to reduce the oil-water interfacial tension. The surfactant (BS-12) interface activity is affected by HAPAM. The required time of interfacial tension balance is longer with polymer concentrations increasing.

(3) When the surfactant (BS-12) concentrations are lower, the apparent viscosity, apparent weight average molecular weights $\left(M_{w, a}\right)$, root mean square radius of gyration $\left(\left\langle R_{g}\right\rangle\right)$, and hydrodynamic radius $\left(\left\langle R_{h}\right\rangle\right)$ of HAPAM increase with the increment of BS-12 concentrations. When surfactant concentrations are $100 \mathrm{ppm}$, they are maximum; surfactant concentrations continue to increase and they begin to decline. BS-12 has a great influence on performances of HAPAM solutions.

(4) The hydrophobically associating polymer (HAPAM) can form the obvious spatial network structures exceeding the critical association concentration (CAC) in distilled water. When added surfactant (BS-12) concentrations are about $100 \mathrm{ppm}$, the space network structures become more intense, and the connecting network chain beams are thicker. BS-12 concentrations continue to increase, when concentrations are about 400 ppm, loose network structures are formed, and partially loose network structures are broken.

\section{Conflict of Interests}

The authors declare that there is no conflict of interests regarding the publication of this paper.

\section{Acknowledgments}

The authors gratefully appreciated the National Science and Technology Major Projects, China (no. 2011ZX05011). The authors appreciated the State Key Laboratory of Oil and Gas Reservoir Geology and Exploitation for experiment help too.

\section{References}

[1] C. Wang, X.-R. Li, and P.-Z. Li, "Study on preparation and solution properties of hydrophobically associating polyacrylamide by emulsifier-free ultrasonic assisted radical polymerization," Journal of Polymer Research, vol. 19, no. 8, pp. 9933-9939, 2012.

[2] S.-L. Cram, H.-R. Brown, M.-S. Geoffrey, D. Hourdet, and C. Creton, "Hydrophobically modified dimethylacrylamide synthesis and rheological behavior," Macromolecules, vol. 38, no. 7, pp. 2981-2989, 2005.

[3] H. Chen, E.-X. Li, Z.-B. Ye, L.-J. Han, and P.-Y. Luo, "Interaction of hydrophobically associating polyacrylamide with gemini surfactant," Acta Physico-Chimica Sinica, vol. 27, no. 3, pp. 671676, 2011.
[4] G.-O. Yahaya, A.-A. Ahdab, S.-A. Ali, B.-F. Abu-Sharkh, and E.-Z. Hamad, "Solution behavior of hydrophobically associating water-soluble block copolymers of acrylamide and Nbenzylacrylamide," Polymer, vol. 42, no. 8, pp. 3363-3372, 2001.

[5] F. S. Hwang and T. E. Hogen-Esch, "Effects of water-soluble spacers on the hydrophobic association of fluorocarbonmodified poly(acrylamide)," Macromolecules, vol. 28, no. 9, pp. 3328-3335, 1995

[6] M. Li, M. Jiang, Y.-X. Zhang, and Q. Fang, "Fluorescence studies of hydrophobic association of fluorocarbon-modified poly $(\mathrm{N}$ isopropylacrylamide)," Macromolecules, vol. 30, no. 3, pp. 470478, 1997.

[7] Y.-J. Feng, L. Billon, B. Grassl, G. Bastiat, O. Borisov, and J. François, "Hydrophobically associating polyacrylamides and their partially hydrolyzed derivatives prepared by postmodification. 2. Properties of non-hydrolyzed polymers in pure water and brine," Polymer, vol. 46, no. 22, pp. 9283-9295, 2005.

[8] P. Deo and P. Somasundaran, "Interactions of hydrophobically modified polyelectrolytes with nonionic surfactants," Langmuir, vol. 21, no. 9, pp. 3950-3956, 2005.

[9] G. Nizri, S. Lagerge, A. Kamyshny, D. T. Major, and S. Magdassi, "Polymer-surfactant interactions: binding mechanism of sodium dodecyl sulfate to poly(diallyldimethylammonium chloride)," Journal of Colloid and Interface Science, vol. 320, no. 1, pp. 74-81, 2008.

[10] A.-E. Goddard, M.-L. Francisco, M.-J. Arturo, and H.-A. Roque, "Two-dimensional colloidal aggregation: concentration effects," Journal of Colloid and Interface Science, vol. 246, no. 2, pp. 227234, 2002.

[11] D.-X. Wang, L. Luo, L. Zhang, Y.-Y. Wang, S. Zhao, and J.$\mathrm{Y}$. Yu, "Study on interfacial interaction between hydrophobically modified polyacrylamide and surfactants," Acta PhysicoChimica Sinica, vol. 21, no. 11, pp. 1205-1210, 2005.

[12] A.-S. Anna, R.-A. Campbell, and C.-D. Bain, "Dynamic adsorption of weakly interacting polymer/surfactant mixtures at the air/water interface," Langmuir, vol. 28, no. 34, pp. 12479-12492, 2012.

[13] N. Beheshti, A.-L. Kjøniksen, K. Zhu, K. D. Knudsen, and B. Nyström, "Viscosification in polymer-surfactant mixtures at low temperatures," Journal of Physical Chemistry B, vol. 114, no. 19, pp. 6273-6280, 2010.

[14] L.-D. Jiang, B.-J. Gao, and L. Gang, "Interaction between cationic Gemini surfactant with hydrophobically associatied polyacrylamide of a new family," Acta Physico-Chimica Sinica, vol. 23, no. 3, pp. 337-342, 2007.

[15] N.-V. Sastry and H. Hoffmann, "Interaction of amphiphilic block copolymer micelles with surfactants," Colloids and Surfaces A, vol. 250, no. 1-3, pp. 247-261, 2004.

[16] L. Piculell, M. Egermayer, and J. Sjöström, "Rheology of mixed solutions of an associating polymer with a surfactant. Why are different surfactants different?" Langmuir, vol. 19, no. 9, pp. 3643-3649, 2003.

[17] G.-L. Smith and C.-L. McCormick, "Water-soluble polymers. 79-Interaction of microblocky twin-tailed acrylamido terpolymers with anionic, cationic, and nonionic surfactants," Langmuir, vol. 17, no. 5, pp. 1719-1725, 2001.

[18] J.-R. Enrique, S. Joseph, and C. Francoise, "Effect of surfactant on the viscoelastic behavior of semidilute solutions of multisticker associating polyacrylamides," Langmuir, vol. 16, no. 23, pp. 8611-8621, 2000.

[19] X.-Y. Wang, Y.-J. Li, J.-B. Wang et al. et al., "Interactions of cationic gemini surfactants with hydrophobically modified 
poly(acrylamides) studied by fluorescence and microcalorimetry," Journal of Physical Chemistry B, vol. 109, no. 26, pp. 1285012855, 2005.

[20] H. Chen, W.-T. Lu, Z.-B. Ye, L.-J. Han, and P.-Y. Luo, "Influence of hydrolysis degree on properties of associating polymers solution," Oilfield Chemistry, vol. 29, no. 2, pp. 190-194, 2012.

[21] E. Minatti and D. Zanette, "Salt effects on the interaction of poly(ethylene oxide) and sodium dodecyl sulfate measured by conductivity," Colloids and Surfaces A, vol. 113, no. 3, pp. 237246, 1996

[22] M. Y. Khan, A. Samanta, K. Ojha, and A. Mandal, "Interaction between aqueous solutions of polymer and surfactant and its effect on physicochemical properties," Asia-Pacific Journal of Chemical Engineering, vol. 3, no. 5, pp. 579-585, 2008.

[23] L.-J. Han, Z.-B. Ye, H. Chen, and P.-Y. Luo, "Self-assembly of hydrophobically associating polyacrylamide and gemini surfactant," Acta Physico-Chimica Sinica, vol. 28, no. 6, pp.14051410, 2012.

[24] H. Chen, X.-Y. Wu, Z.-B. YE, L.-J. Han, and P.-Y. Luo, "Selfassembly behavior of hydrophobically associating polyacrylamide in salt solution," Acta Physico-Chimica Sinica, vol. 28, no. 4, pp. 903-908, 2012.

[25] Q.-W. Zhang, J. Ye, Y.-J. Lu et al., "Synthesis, folding, and association of long multiblock (PEO 23-b-PNIPAM124)750 chains in aqueous solutions," Macromolecules, vol. 41, no. 6, pp. 2228-2234, 2008.

[26] L. Hong, F.-M. Zhu, J.-F. Li, T. Ngai, Z.-W. Xie, and C. Wu, "Folding of long multiblock copolymer (PI-b-PS-b-PI)n chains prepared by the Self-Assembly Assisted Polypolymerization (SAAP) in cyclohexane," Macromolecules, vol. 41, no. 6, pp. 2219-2227, 2008.

[27] D. Xie, X. Ye, Y.-W. Ding et al., "Multistep thermosensitivity of Poly(N-n-propylacrylamide)-block-poly(N-isopropylacrylamide)-block-poly(N,N-ethylmethylacrylamide) triblock terpolymers in aqueous solutions as studied by static and dynamic light scattering," Macromolecules, vol. 42, no. 7, pp. 27152720, 2009.

[28] X. Wang, X. Qiu, and C. Wu, "Comparison of the coil-toglobule and the globule-to-coil transitions of a single poly $(\mathrm{N}$ isopropylacrylamide) homopolymer chain in water," Macromolecules, vol. 31, no. 9, pp. 2972-2976, 1998.

[29] P.-A. Fuierer, B. Li, and H. S. Jeon, "Characterization of particle size and shape in an ageing bismuth titanate sol using dynamic and static light scattering," Journal of Sol-Gel Science and Technology, vol. 27, no. 2, pp. 185-192, 2003.

[30] R. Zhang, Z.-B. Ye, L. Peng, N. Qin, Z. Shu, and P.-Y. Luo, "The shearing effect on hydrophobically associative watersoluble polymer and partially hydrolyzed polyacrylamide passing through wellbore simulation device," Journal of Applied Polymer Science, vol. 127, no. 1, pp. 682-689, 2012.

[31] Y. Dong and D.-C. Sundberg, "Estimation of polymer/water interfacial tensions: hydrophobic homopolymer/water interfaces," Journal of Colloid and Interface Science, vol. 258, no. 1, pp. 97-101, 2003.

[32] M. Nedjhioui, N. Moulai-Mostefa, A. Morsli, and A. Bensmaili, "Combined effects of polymer/surfactant/oil/alkali on physical chemical properties," Desalination, vol. 185, no. 1-3, pp. 543550,2005

[33] J.-X. Liu, Y.-J. Guo, J. Hu et al., "Displacement characters of combination flooding systems consisting of gemini-nonionic mixed surfactant and hydrophobically associating polyacrylamide for bohai offshore oilfield," Energy Fuels, vol. 26, no. 5, pp. 2858-2864, 2012.

[34] Y.-J. Guo, J.-X. Liu, X.-M. Zhang et al., "Solution property investigation of combination flooding systems consisting of gemininon-ionic mixed surfactant and hydrophobically associating polyacrylamide for enhanced oil recovery," Energy and Fuels, vol. 26, no. 4, pp. 2116-2123, 2012.

[35] H.-J. Gong, X. Xin, G. Y. Xu, and Y.-J. Wang, “The dynamic interfacial tension between HPAM/C17H33COONa mixed solution and crude oil in the presence of sodium halide," Colloids and Surfaces A, vol. 317, no. 1-3, pp. 522-527, 2008.

[36] S. Badoga, S.-K. Pattanayek, A. Kumar, and L.-M. Pandey, "Effect of polymer-surfactant structure on its solution viscosity," Asia-Pacific Journal of Chemical Engineering, vol. 6, no. 1, pp. 78-84, 2011.

[37] L.-D. Jiang, B.-J. Gao, and L. Gang, "Interaction between cationic Gemini surfactant with hydrophobically associatied polyacrylamide of a new family," Acta Physico-Chimica Sinica, vol. 23, no. 3, pp. 337-342, 2007.

[38] Y.-J. Mei, Y.-X. Han, H. Zhou, L. Yao, and B. Jiang, "Synergism between hydrophobically modified polyacrylic acid and wormlike micelles," Acta Physico-Chimica Sinica, vol. 28, no. 7, pp. 1751-1756, 2012.

[39] R. Zhang, Z.-B. Ye, and P.-Y. Luo, "The atomic force microscopy study on the microstructure of the polymer solution," Journal of Chinese Electron Microscopy Society, vol. 29, no. 5, pp. 475-481, 2010. 

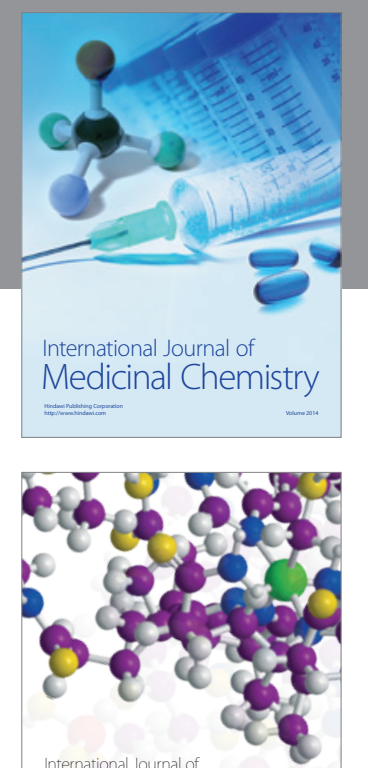

\section{Carbohydrate} Chemistry

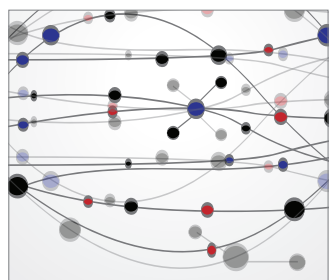

The Scientific World Journal
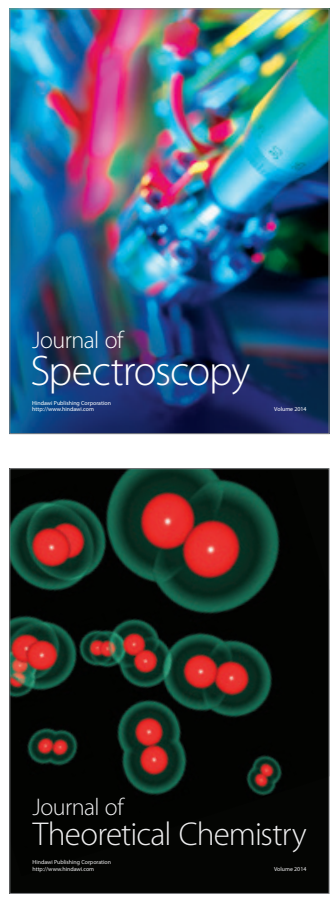
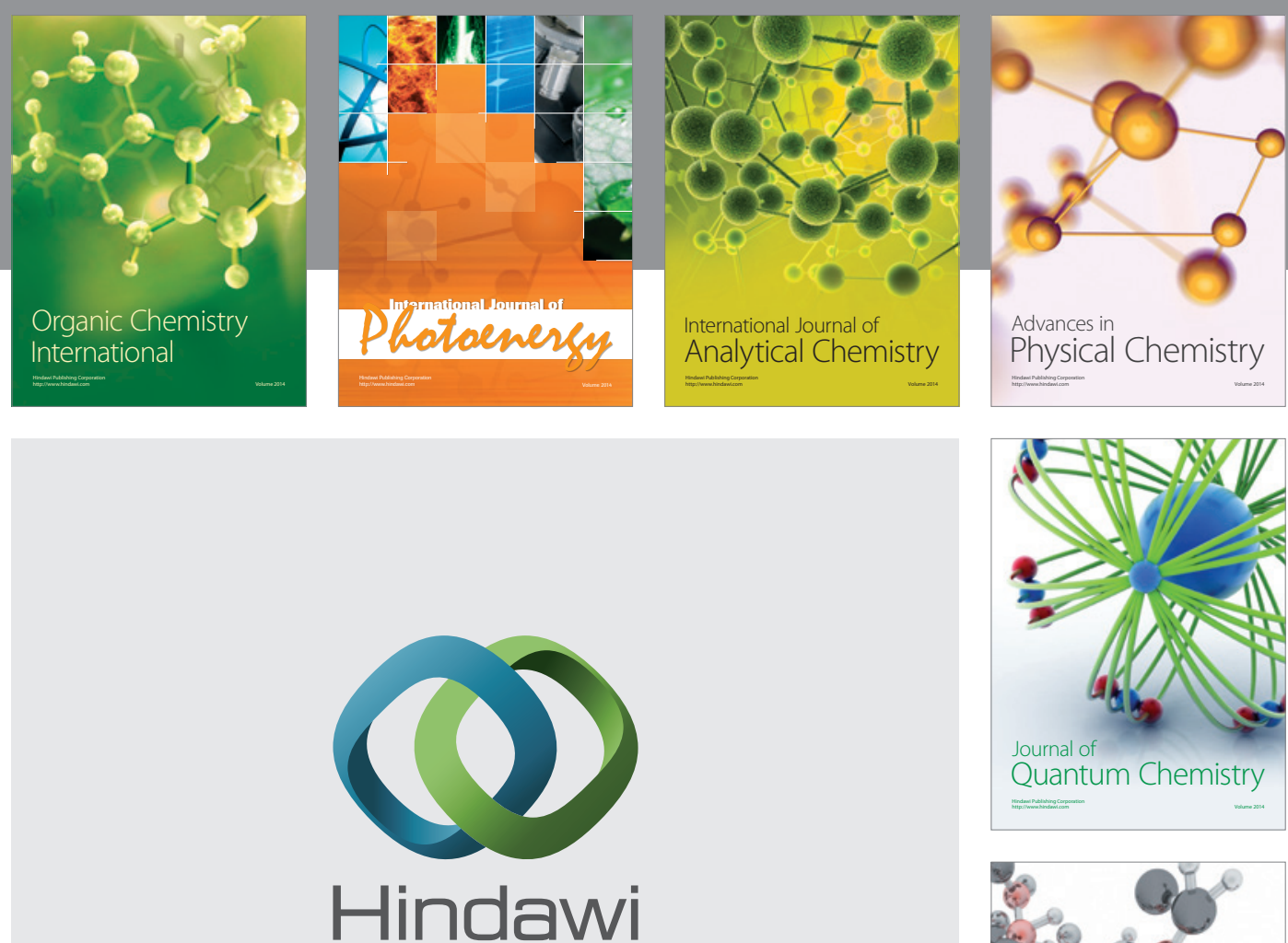

Submit your manuscripts at

http://www.hindawi.com

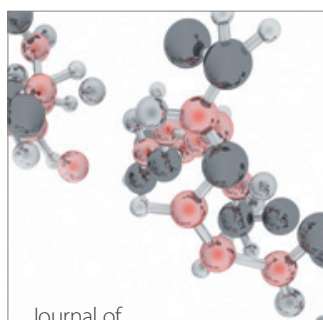

Analytical Methods

in Chemistry

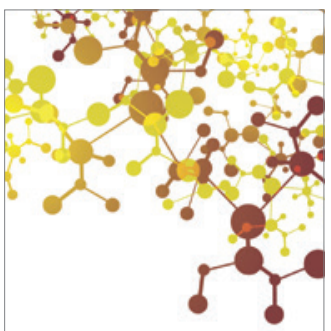

Journal of

Applied Chemistry

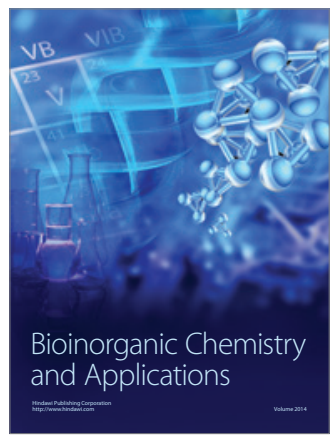

Inorganic Chemistry
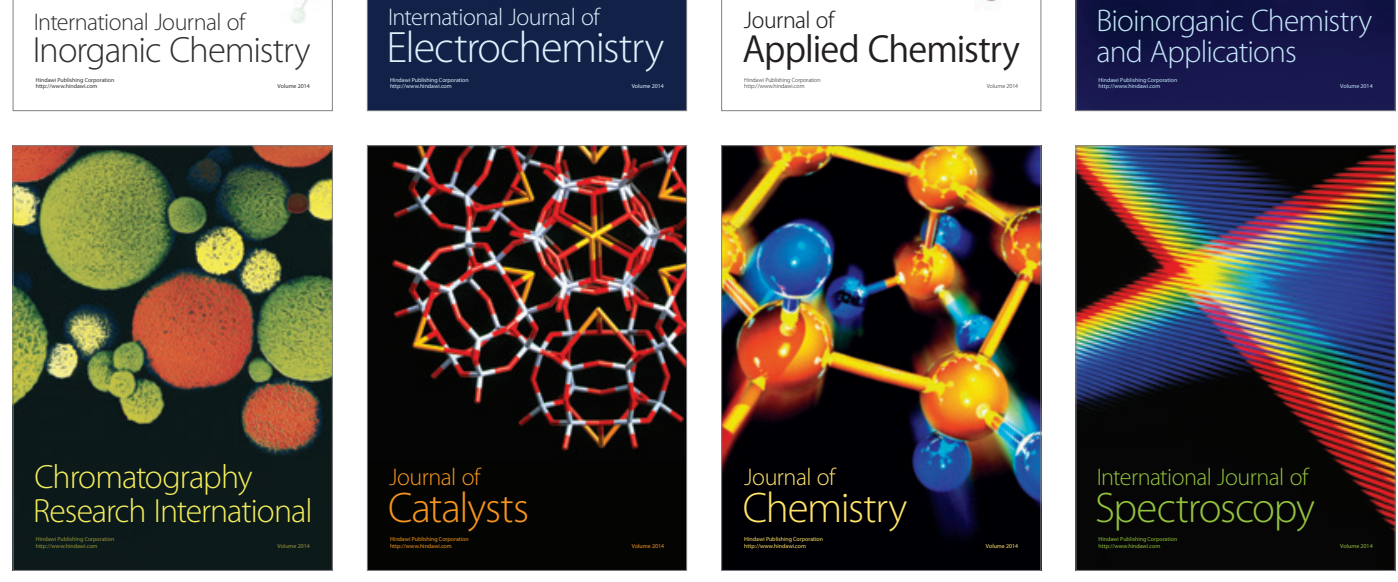